\title{
Scottish fashion influencers: constructing a style identity on Instagram.
}

\author{
MARCELLA-HOOD, $\mathrm{M}$.
}

2020 


\section{Abstract}

This article builds on existing theories of self presentation and identity through a study into the behaviour of fashion influencers who position themselves as Scottish on Instagram. Fourteen interviews were carried out with Scottish fashion influencers who were asked to reflect on their online identity.

The interaction between the offline and online self is explored, where national identity and a sense of place are recognised as important attributes of self identity in an offline setting and participants were sampled on the basis that they were projecting this as a key component of their online self. All were found to be seeking to convey an ideal identity on Instagram; this involved curating particular aspects of their offline style and showcasing these online.

The issue of authenticity was complex and a spectrum of identity evolution on Instagram is observed and reflected on. The most career-minded participants tended to portray themselves in a more one-sided manner and were most strongly influenced by a sense of their audience. In contrast, the participants who were less career minded tended to explore more freely with their online self and were influenced most strongly by internal factors.

\section{Scottish fashion influencers: constructing a style identity on Instagram}

The popularity of personal fashion blogs and their influence is explored quite extensively in the literature (e.g. Chittenden, 2010; Pham, 2011; Rocamora, 2011b; McQuarrie et al, 2013; Pedroni, 2017). Indeed the influence and impact of opinion leadership in the context of fashion and style has been debated for some time (Summers, 1970). Early fashion bloggers are credited with having democratised an industry that was previously reserved for the elite (Allen, 2009) and it could even be argued that fashion bloggers have achieved a celebrity-like status through the accumulation of high numbers of followers with similar aesthetic tastes (McQuarrie et al, 2013; Pedroni, 2017). This extends beyond a purely online position, whereby they have consistently, and for some time now, 
appeared in the front row of high-profile events alongside editors, designers, critics and more traditional celebrities (Hänninen, 2015). Where fashion bloggers were once admired for appearing real and relatable, many now appeal on a more aspirational level, leading what could be regarded as a celebrity lifestyle that includes free goods gifted from brands and travelling the world (Duffy and Hund, 2015; Findlay, 2015; Pedroni, 2017). This commercial aspect and the monetisation of fashion blogs has, of course, led to questions and doubts about the authenticity of the lifestyle that is presented by these individuals (Marwick, 2013; Pedroni, 2017; Rocamora, 2018).

As social media has evolved, so has the definition of fashion bloggers, who are now more typically termed "influencers" (Abidin, 2016: 86). This is in recognition of the extent to which they operate primarily through other social media platforms and have attracted such interest from brands that employ them to help market their products (ibid). Fashion influencers reveal aspects of their "dressed identity" (Findlay, 2015: 171) through a series of posts, comprising of visual (photographs and/ or videos) and written communication in the form of captions, hashtags and, in the case of bloggers, longer posts. Much of their success today is reliant on the portrayal of an identity that strikes the right balance between relatable and aspirational and where this is communicated in a consistent and engaging manner to a digital audience (Song, 2016). Fashion influencers, therefore, have allowed their audience access to fashion inspiration in an instantaneous manner, providing a more personal and backstage glimpse into a life lived fashionably than was previously accorded by other forms of media, like magazines (MacDowell and de Souza e Silva, 2018). The informal and personal style of their communication has arguably made even the mere concept of fashion more inclusive.

Instagram is recognised as a visual platform that lends itself particularly well to creativity and self expression (Sheldon and Bryant, 2015; Dumas et al, 2017; Liu and Suh, 2017). Users can construct an online identity using photographs, videos and written text, in ways similar to fashion blogs (Chittenden, 2010; Rocamora, 2011; Luvaas, 2013; Titton, 2015; dePerthuis and Findlay, 2019). Instagram has 
also been described as a tool for self-promotion (Dumas et al, 2017) and is linked strongly with the phenomenon of micro-celebrity and self-branding (Duffy and Hund, 2015; Maghfiroh and Hapsari, 2015; Marwick, 2015; Abidin, 2016; Liu and Suh, 2017). Fashion influencers that operate on the platform are recognised as a particular example of this phenomenon, evolving from the wave of fashion bloggers that revolutionised the industry before them (Rocamora, 2011; Abidin, 2016). Instagram is seen today as the logical starting point for a fashion influencer (O’Brien, 2016) and some even argue that the platform might eventually eclipse traditional blogs completely (Klein, 2014; Blalock, 2016).

A career as a fashion influencer is regarded today as a viable job prospect for fashion graduates and style-conscious individuals. With increasing exposure to successful influencers, the appeal of the lifestyle they present, easy access to social media and the lure of sponsorship opportunities, it is not difficult to see how this becomes an attractive prospect to those with an interest in fashion. The fact that so many people operate on these platforms anyway blurs the boundaries between personal and professional social media usage, making it possible to test the professional waters whilst at school, university, whilst raising children or in full-time employment.

Rocamora (2018: 68) explores fashion blogging as a form of "immaterial labour", where career-orientated bloggers (or influencers) engage in commercial practices that are separate from what would normally be regarded as work effort. There appears to be a tension between the idea of a blogger wishing to remain authentic and invested in blogging for their own enjoyment versus their desire for acceptance from followers around brand partnerships and appreciation for the effort they put into creating content; where labour might include writing, photography, styling and even responding to messages and comments from followers. In this way, Rocamora argues that fashion blogging "is both occupation in the making and occupation being made by its makers through practice and discourse on the practice itself", where many bloggers will discuss this work effort and aspects of their occupation as a blogger openly with their followers. This echoes Pedroni's (2017: 118) argument that "there is no longer 
any prejudice or false indignation about gaining financial capital" amongst bloggers/ influencers.

One fashion blogger turned influencer, Aimee Song, published a book in 2016 documenting her style success on Instagram, claiming the platform helped take her fashion blog to new levels of success; providing access to new communities, including brands and audiences. Although she maintains a blog, Instagram is clearly fundamental to her career as a fashion influencer. Her book, Capture Your Style, is a toolkit designed firstly to raise her own profile as a leading fashion influencer and secondly to provide advice for others looking to build an audience on Instagram. In particular, she highlights storytelling, engagement and immediacy as important features of the platform. She stresses the importance of being "real" (84) and refers to a hypothetical contrast between the "organic" and the "curated" self (60). The fact that such a book even exists illustrates the extent to which online identity construction has become widely accepted, embraced and engaged in by the masses.

Place is at the core of the Instagram app, where its Geotag feature enables users to add a location to their post. Once added, this acts as a clickable link where users can access a visual map and enjoy other images of that place, "turning Instagram into [their] own city guide" (Song, 2016: 32). The platform has attracted interest in the field of cultural studies where it is argued that Instagram has transformed "amateur photography", which is "immersed in the texture of every-day life" and increasingly accessible to a wide audience (Utekhin, 2015: 185).

Fashion influencers are cited as an example of creative entrepreneurialism that is particularly observable amongst women (Duffy and Hund, 2015). The phenomenon of personal style and the ease with which one can convey this publicly to a mass audience using platforms like Instagram has undoubtedly disrupted the fashion industry. The digital media landscape is dynamic and unpredictable but the so-called influencer economy shows no sign of slowing down (Abidin, 2016; Penchansky et al, 2018). In order to be successful, 
influencers must seek new ways to be distinctive and stand out within this increasingly crowded realm (Casaló et al, 2018).

As the number of fashion influencers has grown steadily over recent years, it becomes progressively difficult for these individuals to establish and set themselves apart in such a crowded realm. The current article builds on existing theories of self presentation and identity through an investigation of fashion influencers who position themselves as Scottish on Instagram. The aim of this study was both to explore the career and identities of Scottish fashion influencers on Instagram and to investigate how their online self was influenced by a sense of national identity and physical place.

The article begins by discussing existing literature that considers the significance of place in fashion blogging and social media production. The construction of online identity and applicability of some of the more classic theories of identity are then explored. A description of how the phenomenon was investigated is provided in the methodology section, followed by a discussion of the findings. Conclusions are drawn as to this article's contribution to the field of fashion studies.

\section{Place in fashion blogging and social media production}

Although fashion bloggers, turned influencers, have been explored quite extensively in the literature, there are relatively few studies that acknowledge the relationship between a blogger and their sense of place (Palmgren, 2010; Lövheim, 2013; Luvaas, 2013; Hänninen, 2015; Pedroni, 2015; Tomiuc and Stan, 2015; Pedroni, 2017). These initial studies suggest that fashion bloggers might form communities based on physical place and that these might result in a shared aesthetic or style. Despite some of their focus on non-traditional fashion destinations, these studies note a blogosphere evolution, which aligns to the global trajectory; where these began as candid and informal and have gradually become more professional in their approach and commercialised in their 
content. Although these studies provide valuable insights into the phenomenon of fashion blogging within national contexts, they do not set out to explore how a sense of national identity and place might actually influence the online self.

Luvaas (2013) studies Indonesian fashion bloggers and observes the notion of place and placelessness, where some are highly selective in the locations that they choose to share. This is supported by the work of Schwartz and Halegoua (2015: 1644) who observe the construction of a "spatial self" on Instagram, which they argue is central to how users convey their identity online, using place (which might be as specific as a restaurant or as broad as a nation) as a form of symbolic capital (Bourdieu, 1986).

Hänninen (2015) found that the self perception of being independent, honest and hard-working was important to Finnish fashion bloggers but that commercialisation of the blogosphere had been slower in Finland than in what might be considered more developed blogging nations like Sweden (Palmgren, 2010; Lövheim, 2013). Tomiuc and Stan (2015: 116) investigate fashion blogging in Romania and argue that social media could play a significant role in shaping conceptualisations of the nation's fashion industry. They refer to "personal style blogs" as "self-centred fashion blogs" and found these to be the most prominent category of blog in Romania. They also note the significance of Instagram as an outlet through which bloggers can express themselves visually and engage with their followers most effectively.

Scotland, like Finland and Romania, might be considered as more of a developing fashion blogging nation. The Scottish fashion infosphere has grown and is evolving but not at the same rate as other national contexts, e.g. more traditional fashion destinations and hubs, such as Italy and Sweden (Palmgren, 2010; Lövheim, 2013; Pedroni, 2015). Scotland does not have a strong fashion media infrastructure, consisting mostly of local lifestyle publications, and so fashion influencers operating on global platforms like Instagram might be considered particularly valuable in communicating contemporary illustrations of Scottish fashion and style. 


\section{National identity and fashion}

There is increasing academic interest in national fashion systems and a growing body of work in this area (Mora and Rocamora, 2015), which synthesises a vast number of studies, spanning issues of gender, race and ethnicity. Indeed, Scottish identity itself is a key area of academic enquiry and one that has become reinvigorated in recent years, during the run up to and aftermath of the Scottish Independence Referendum in 2014. Scottish fashion, on the other hand, is an underdeveloped area of research and studies that do exist focus on the production of traditional textiles like tartan and tweed (Marcella-Hood, 2019). These studies cannot all be included within the scope of this paper but some of the most relevant work is highlighted and explored.

Scottish identity is seen as distinctive in global settings, where dominating symbols include "items of material culture" (e.g. Scottish tartan) and placerelated signifiers (e.g. Scotland as a vast and peopleless landscape) (McCrone et al, 1995; Crane et al, 2004: 67). Craik (2009: 410) explores the distinctiveness of Australian fashion and the challenges in defining national dress. She found that a sense of place, a sense of body and a sense of cultural heritage were distinct aspects of Australian style and defines a national sense of style as communication of the "zeitgeist of a place..." (ibid: 413).

Craik (2009) and Segre Reinach (2015: 267) both explore the aesthetics of "national creativity" or the components that make a garment or style unique or different. Scotland's national creativity could be described as strong, represented most effectively through its textiles (e.g. tartan, tweed and wool). Craik's notion of cultural practice refers to the acceptance of that fashion or style and rules as to when it should be adopted, e.g. the kilt as formalwear. Cultural articulation, she argues, is where the style has become established both internally and externally as belonging to that country, as is certainly the case with Scottish textiles, which are referenced regularly by global fashion designers (Young and Martin, 2017; Marcella-Hood, 2019). Indeed, Skov (2010) argues that fashion designers are important signifiers of their national identity. 
Riegels Melchior (2010, p. 36) investigates the relationship between national identity and fashion design further through a case study of a Danish fashion company. McCrone at al (1995) argue that Scotland's iconography is so distinctive that it is difficult for contemporary ideas to flourish. Meanwhile, Riegels Melchior (2010) maintains that Danish fashion has the reverse problem, whereby designs tend not to be attributed to Denmark as a nation because they are not immediately recognised as part of an existing aesthetic. However, this still suggests that symbols like Scottish tartan are likely to dominate.

Goodrum (2009) explores the export of national identity in fashion through a case study of two luxury fashion brands. She found that ethnic or national symbols are important and that these should take audience perceptions into account. Some of these studies cite the importance of authenticity in the production of national fashion identity (Goodrum, 2009; Segre Reinach, 2015). In these examples the reception of identity was found to be most successful when perceived as genuine and real. This again highlights authenticity as a theme that permeates literature in the fields of identity, national identity, Scottish identity and fashion.

It is important to note that, as with fashion and style more generally, national identity as communicated through dress, is not fixed. Items will become dated, experience periods of resurgence and some styles might disappear completely (Craik, 2009); e.g. it has been argued that the Scottish kilt has experienced a revival. Indeed, national fashion and style and the rules surrounding this are contextual and, what is culturally appropriate in one setting by one individual could be deemed inappropriate in another (Craik, 2002); for example, a kilt would be regarded as acceptable as formalwear but generally not in work or more casual settings. However, there are some examples where fashions have appeared and been accepted out of context, such as the adoption of Scottish textiles (particularly tartan) by dominant subcultures, which further illustrates the fluidity of fashion and style. 
In her study Fashioning the City: Paris, Fashion and the Media, Rocamora (2009: 127) reflects on the relationship between place, fashion and identity and how these are conveyed through street style:

Vestimentary styles are also the means by which, in the chaos and anonymity characteristic of city life, strangers who pass each other by in the street create sense and meaning by seeing clothes as a legible surface that can reveal the other's personality.

Rocamora argues that Paris, like Scotland, has achieved something of a mythical status, through its rich iconography and discourse. It is argued that, as with fashion designers and brands, fashion influencers (who position themselves outwardly as "Scottish" on Instagram) might represent a new kind of cultural icon through which Scottish fashion and identity is communicated and understood. The current research helps to uncover how these individuals can add to the narrative of Scottish identity by exploring how a sense of national identity and place informs their online self and career as an influencer.

\section{Identity construction on blogs and social media}

It has been argued that identity studies "cannot reasonably ignore psychoanalytic and social science and the studies situated within these" (Hoover, 2004: 3). Th current article draws on the works of Erikson and Goffman, in particular, applying their respective theories of identity evolution (Erikson, 1959) and self presentation (Goffman, 1956) to the study of Scottish fashion influencers on Instagram.

Erikson (1959) is said to be the first to apply identity in psychoanalytical research (Hoover, 2004). His work has since been evolved beyond the field of health sciences and the adolescent population upon which his ideas were formed. Hoover's (2004) work The Future of Identity brings together the work of a group of theorists who have advanced Erikson's ideas within social sciences 
and these studies were useful in helping understand the ways in which his ideas could be applied to the current research.

Erikson (1959) found personal identity to be an evolutionary process whereby an individual travels internally from a place of confusion to the achievement of a true self. Although he focused on adolescents, he theorised that this crisis of identity occurs in other developmental phases throughout an individual's life, where they seek to achieve an identity that is shaped by their contextual surroundings. It is argued that individuals will assume functions and beliefs that they feel support their idealised self, where "identity formation is an evolving, deepening sense of psychosocial commitment and of knowing what is worthy of one's fidelity in this world of many possibilities" (Kroger, 2004: 66).

Goffman (1956: 26) approaches identity from a sociological perspective and argues that individuals construct and manage their identities in a conscious manner, with underlying "motives" for doing so, whilst Erikson believes that there will be unconscious shifts. Although criticised for lacking a clear methodology and empirical underpinning, Goffman's work is celebrated for its originality (Scheff, 2006). In the study of online identity, it is difficult to ignore the applicability of both Erikson and Goffman's theories, which together consider the internal and external motivations for constructing the self.

Butler's (1988: 519) ideas are recognised as applicable to blogs and social media (Van House, 2009; Findlay, 2015; Schwartz and Halegoua, 2015). Like Goffman, she considers the performative aspect of identity in what she terms the "stylised repetition of acts". However, unlike Goffman, Butler suggests that identity is influenced not so much by social motives but by common cultural discourse and points of reference, like national identity. She posits gender as a particular example of "constructed identity, a performative accomplishment which the mundane social audience, including the actors themselves, come to believe and to perform in the mode of belief" (520). 
A new variant on the story of Narcissus, people are able to fall in love with the artificial worlds that they have created or that have been built for them by others (Turkle, 1995: 30).

Turkle (1995) in her work Life on the Screen explores the construction of online identities at a time when the Internet was in its infancy and the online self was a relatively new phenomenon. The construction of online identity has since been explored in a number of settings; for example Hardey (2002: 571) investigates the relationship between online and offline self in the context of Internet dating. He distinguishes between the "embodied self" and the "disembodied cyberself", where hypothetically the latter is not constrained by attributes such as race or gender. However, Hardey argues that "virtual spaces may be shaped by and grounded in the social, bodily and cultural experiences of users", particularly where relationships are anchored between online and offline (Zhao, 2006: 110).

Turkle's study predates social media as it is understood and used today but could be regarded as ahead of its time in the extent to which her ideas remain applicable in a wider array of contexts. Indeed, as blogs and social media have increased in popularity, the phenomenon of online identity has continued to attract the interest of academics.

Bullingham and Vasconcelos (2013: 107) explore the applicability of Goffman's framework through a study of bloggers' motivations and behaviour. They propose the blog as a metaphorical stage through which the frontstage self can be "embellished". In this manner, bloggers reveal aspects of their backstage, offline identity online but are selective in the experiences and attributes they choose to share often highlighting what they perceive to be the best bits. Hogan (2010: 377) also applies Goffman's theories to the study of online identity, distinguishing between "exhibitions" (in for example the single act of sharing a particular photograph or set of photographs) and "performances" (which are a result of an ongoing attempt to manage followers' impressions of oneself). The latter idea might easily be applied to the way in which fashion influencers construct their identities online. 
Van House (2009: 1074) explores Goffman and Butler's theories in her study Collocated Photo Sharing, Story Telling and the Performance of Self. She investigates "personal photography as a culturally and socially situated activity" in the field of human-computer interaction, at a time where photo sharing was growing with the aid of digital cameras, camera phones and applications. Her study predates Instagram but resonates with the way in which people use the platform today. Van House found that images can be used collectively as part of a "collocated digital feed" to convey a story about a particular person or group.

Although Goffman and Butler's theories are cited in studies of fashion blogging and online identity construction (e.g. Palmgren, 2010; Bullingham and Vasconcelos, 2013; Findlay, 2015; Harju and Huovinen, 2015), Erikson's work is not fully explored, despite its potential applicability. Online identity construction has become commonplace and (in many cases) individuals have been constructing their identities for a relatively long period of time. The phenomenon of the fashion blogger is recognised from around 2007 (Findlay, 2015), Instagram's popularity has increased rapidly since its launch in 2010 (Abidin, 2016) and Pedroni (2017) maintains that the fashion blog has transitioned into a new era. Perhaps, therefore, the time is right to build on the work of Hoover et al (2004) by exploring Erikson's ideas around the more evolutionary aspect of online identity as well as both the internal and external motives that underpin its construction.

In their study of fashion influencers on Instagram, dePerthuis and Findlay (2019: 221) found these individuals represent a new kind of "fashionable ideal", albeit one that is not far removed from what is presented by traditional fashion media (i.e. magazines and catwalks). Their study is informed by the visual analysis of two leading "macro" influencers with large followings who engage in brand collaborations (222). They argue that these influencers are not revolutionary in their content but post variations of the same ideas and conform to similar conventions, where their imagery is typically made up of three components: clothing, body and setting. 
Titton (2015: 202) explores the construction of online identity amongst fashion bloggers and puts forward the "fashionable persona... as a situated, narrative, and performative character developed by bloggers specifically for their blogs that is anchored simultaneously in the blogger's self-identity and in the enactment of collective cultural narratives". Similarly to Turkle's (1995) definition of online identities, Titton describes the fashion blog as a cultural artefact, supporting the argument that Scottish influencers and their content might be regarded as valuable reproductions of the nation.

The concept of authenticity is something of a talking point for academics in the field of fashion studies and, in fact, amongst influencers themselves. In its early days, fashion blogging was seen as more genuine than traditional media where, perhaps for the first time, fashion was being communicated from the perspectives of the real women (or men) wearing it. However, there has been something of a shift in this mindset, where the commercialisation of fashion blogs and platforms like Instagram has led to a movement towards the label "influencer". A subsequent debate has followed around whether these individuals project real styles and experiences and how/ if their authenticity can be measured as well as what authenticity in this context actually means. It is argued that, in the context of fashion blogging / influence, authenticity might comprise three parts: 1) truthful and candid content; unaffected audience interaction; and disclosure of sponsored/ gifted items (Marwick, 2013).

Authenticity is a theme that underpins this study. This is concerned not just with the construction of the online identities but also of Scotland as a national identity: where it is argued that conceptualisations have become romantic and stylised through the promotion of common heritage symbols such as Scottish tartan (McCrone et al, 1995). Equally, it is argued that, in trying to make sense of their own identities, people tend to look towards their heritage as a form of "cultural capital" (McCrone et al, 1995: 20; Bourdieu, 1986). They describe the authenticity of Scottish heritage as a tension between "what is real and what is believable" (McCrone et al, 1995: 20). These ideas are significant, not just in the context of Scotland and national identity, but perhaps also in relation to identity 
more generally in terms of how Scottish fashion influencers construct "the magic of the real" when portraying themselves online (ibid, 86).

In the early days of the Internet, when online identities and interest groups first came to the fore it was suggested that these might actually contribute to the demise of nationhood as a construct (Billig, 1995). It was predicted that this seemingly fixed marker of identity might become less significant in an increasingly digital and global world where other more salient identities might come to the fore. However, as individuals reveal more of themselves online through visual platforms like Instagram and as the infosphere has expanded and evolved, national identity and place appears to be meaningful, where a number of influencers choose to reveal this candidly as part of online biographical descriptions and within their posts. This current research explores Scottish identity and place, in order to draw broader conclusions around how fashion influencers construct their identity online and how their national identity forms part of this.

\section{Methodology}

This article examines the experiences and motivations of fourteen fashion influencers who characterise themselves as Scottish or Scotland-based on Instagram. Criteria for inclusion in the study was simply the use of a Scottish identity and a public Instagram profile where hashtags were used regularly and where the content included fashion as a prevailing theme.

The decision to focus on Scotland was a matter of convenience to the researcher who was living in Scotland and therefore familiar with the language, culture and society of the population being studied. The research might be considered timely, where a growing fashion influencer community in Scotland and a gap in the literature surrounding contemporary Scottish fashion are recognised. 
The term "influencer" became recognised in a fashion context from around 2016 (Abidin: 86) and, since then, there have been further attempts to subcategorise and classify influencers, usually based on follower numbers. The participants in this study could be considered as nano-influencers (under 1, 000 followers) or micro-influencers (1, 000-100k followers) (Au-Yong-Oliveira et al, 2019) with follower numbers ranging from 428 to $54 \mathrm{k}$ (Table 1). They each represent different stages in their Instagram career (Pedroni, 2015) and, although most of them had been active on the platform for a number of years, some had only recently begun using this in what they described as a more "professional" manner (Pedroni, 2017: 118). In this sense, professionalism is expressed through the time and effort participants put into styling and curating their imagery and the maintenance of a public profile, using hashtags to generate engagement, etc.

Pedroni (2017) argues that fashion bloggers can be seen as opinion leaders and tastemakers within a national context, where even those with smaller follower numbers might achieve a localised celebrity status. It could be argued that some of the influencers in this study had achieved this, certainly in a city-wide context. Some felt their content was immediately discernable as belonging to them and spoke of being recognised in offline settings.

\begin{tabular}{|l|r|r|r|}
\hline \multicolumn{4}{|c|}{ Table 1: Participant profiles } \\
\hline Name & \multicolumn{1}{|l|}{ Age } & \multicolumn{1}{l|}{$\begin{array}{l}\text { Date of } \\
\text { Instagram }\end{array}$} & $\begin{array}{l}\text { No. of } \\
\text { followers }\end{array}$ \\
\hline Arran & 25 & 2012 & 7,378 \\
\hline Barra & 26 & 2013 & 428 \\
\hline Cara & 21 & 2012 & 6,446 \\
\hline Danna & 27 & 2013 & $17.8 \mathrm{k}$ \\
\hline Eday & 20 & 2015 & 2,175 \\
\hline Fara & 30 & 2013 & 5,223 \\
\hline Gunna & 24 & 2013 & 1,573 \\
\hline Hirta & 24 & 2013 & 511 \\
\hline Iona & 23 & 2013 & 1,556 \\
\hline Jura & 25 & 2013 & $54 \mathrm{k}$ \\
\hline Lungay & 24 & 2012 & 1,949 \\
\hline Mull & 29 & 2012 & 1,942 \\
\hline Skye & 23 & 2011 & 597 \\
\hline Tiree & 19 & 2012 & 709 \\
\hline
\end{tabular}


Scotland is recognised as a small nation, with a population of 5.4 million (National Records of Scotland, 2019). Knowledge of the Scottish fashion influencer population is imprecise but few had broken the barrier of $50 \mathrm{k}$ followers at the time of carrying out the research. Participants all had blogs and, throughout the interviews, they tended to refer to themselves as "bloggers" rather than "influencers", which suggests a more humble approach to their status and profession.

This research followed the Interpretative Phenomenological Analysis (IPA) approach (Smith, 2004), taking a wholly qualitative approach to data collection and interpretation. The study was inductive, where the purpose was to build on existing theories of identity with primary research. The data set consisted of 14 interview transcripts and a corpus of 77 Instagram posts that participants were asked to select and provide in advance of the interview. This photo-interview approach is different to traditional photo elicitation, where the researcher will usually select the imagery (Collier, 1957). These posts were used as an aid to encourage deeper reflection on the part of the participant influencers, as well as forming a data set for further analysis to inform conclusions about their communication of Scottish identity. In this sense, the interviews were semi structured and lasted around one hour, with participants each selecting between 4 and 12 posts. Interviews were conducted face-to-face or via video call depending on the preference, availability and location of the influencer.

In line with the IPA approach, in-depth analysis of data was carried out whereby the interviews were transcribed and analysed using NVivo. The analysis of participants' imagery was informed by Barthian semiotics (1957) and Panofskian iconology (1955), where the denotation and connotation of each image were considered (Barthes, 1957), as well as the contextual meaning behind these (Panofsky, 1955). Context was drawn from the accompanying caption and also the participant's description of the image during interview. After the two data sets (transcripts and imagery) were analysed separately, they were considered together in order to uncover common themes (Larkin and Thomson, 2012). 
The IPA approach advocates the idea that a finding is not necessarily more significant because it occurs across a number of interviews; the analysis should be idiographic and consider the deep lived-in experiences of social actors being studied (Smith, 2004). Pen portraits were produced for each participant influencer, who were given a pseudonym in order to personalise their responses but maintain a degree of neutrality across the sample, e.g. where no one participant would be seen as more Scottish than another due to their name. An example pen portrait has been set out below:

Eday is an Edinburgh-based student and passionate about Scottish fashion, culture and politics. She was reluctant to categorise herself as wholly Scottish due to the fact she was born and had spent most of her life in Birmingham. She presented strong opinions on what she feels is a lack of a Scottish fashion industry, and saw it very much as the role of style influencers, like herself, to promote this. Her enthusiasm is visible in the images she chose where she is, in her own words, "championing" Scottish brands in all the sample posts. Most of these appear stylised, suggesting she is conscious in her communication of these.

The following discussion explores some of the key themes that were uncovered in this research: firstly in terms of how Scottish fashion influencers construct their identities online; and secondly in terms of how a sense of national identity and place forms part of this identity.

\section{Constructing a style identity online using Instagram}

"My Instagram is not my reality", "a fantasy of myself", "the best bits"... are some of the phrases that participants used to describe their Instagram identity. Although these Scottish fashion influencers felt they portrayed a genuine version of themselves online using Instagram, they were selective in the styles, places and experiences they chose to convey (Bullingham and Vasconcelos, 2013). There were times when participants admitted to planning offline activities for 
the sole purpose of sharing these on Instagram. One participant revealed:

Sometimes I'll see the picture or I'll see a shot and I'll think, "oh that'll look really good on my Instagram". Sometimes it is more spontaneous. But, to be honest, that "People Make Glasgow" one was totally preplanned (laughs). I dragged my boyfriend up the top of the lighthouse so I could take that picture and that was a lot of steps. I was like "this is just for my Instagram!" (Cara, 21).

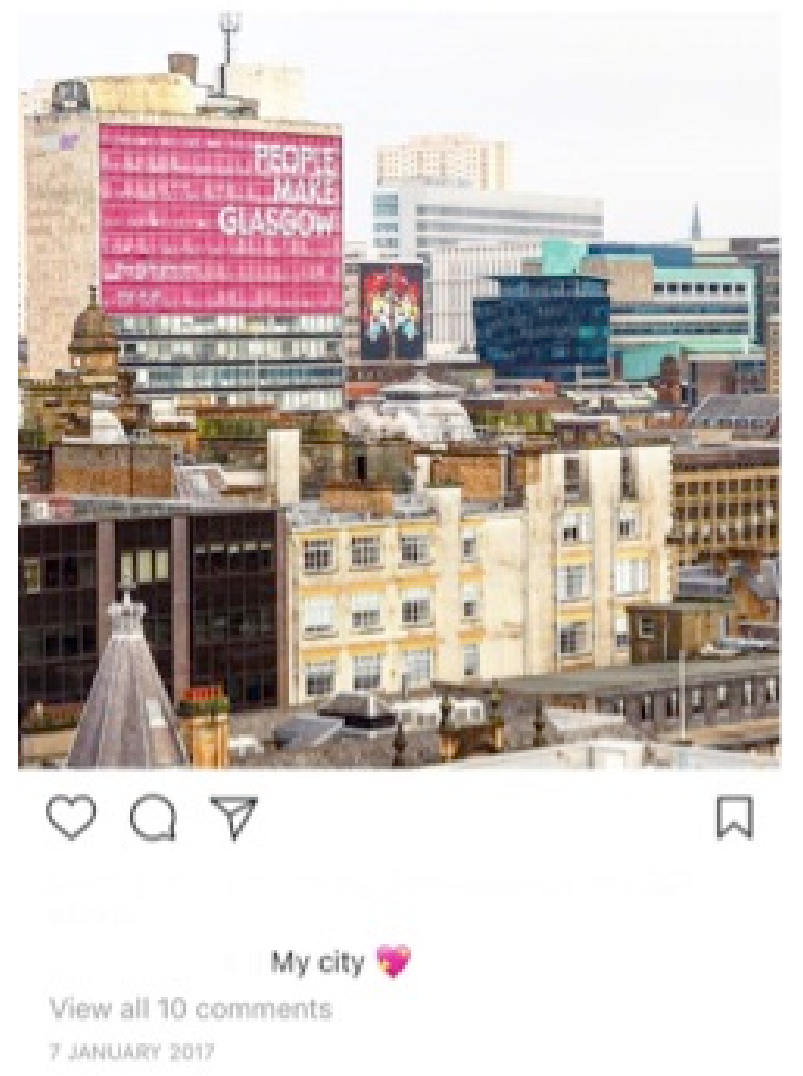

Figure 1: Cara's city identity

Although Instagram is predominantly used as a mobile application, albeit one that enables users to edit their images using filters (Song, 2016), some participants preferred to take photos on a professional camera and edit using specialist software before sharing these with their followers. This is an arduous process but one that they felt was valuable in helping them appear more professional. In line with Song's (2016) advice, participants were found to portray genuine offline moments but often in a highly stylised way. Through the 
selectivity in the experiences they chose to share and the stylisation of their imagery, participant influencers were found to be both curating and constructing their identity online using Instagram. One participant revealed:

I mean my Instagram is not my reality. Judging by my Instagram, you might think that I travel a lot of time, that I might live in the most beautiful place, that my mornings are relaxed and all that when my life is the most hectic life! I'd never imagine my life to be like that... When people are in their offices and they have a lunch break they like scrolling through pictures and travelling with me in a way (Fara, 30)

Another participant claimed to have "a ridiculous amount of confetti on standby" (Cara, 21) which she used to style flat-lay images (Figure 2). A third spoke of taking "like 50 pictures of a cake before being happy and even then thinking 'it's still not the best it could be'" (Barra, 26).

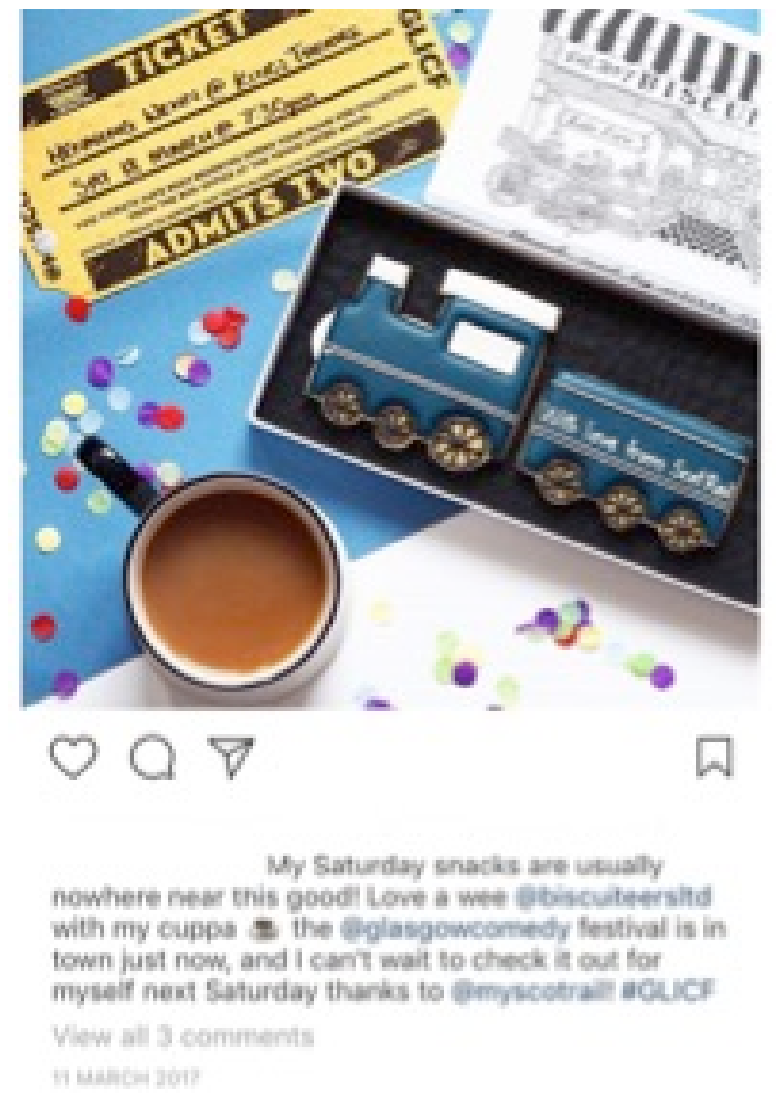

Figure 2: Flatlay style image 
These examples suggest the frontstage identity that is presented on Instagram might not always be acted out in real-time backstage (Goffman, 1956). Indeed, posts might be held and shared sporadically in order for an influencer to retain a level of regularity in their output. Some participants spoke about stockpiling imagery in this way; for example, teaming up with other Scottish fashion influencers to "shoot" and create content for Instagram. In some cases, participants disclosed this in the accompanying caption, which again illustrates that identity construction is not only common amongst influencers but is also accepted by their followers. It also supports the idea that Scottish fashion influencers have an open and honest dialogue with their followers, in line with Hänninen's (2015) description of Finnish bloggers.

Figure 3 shows one participant's commitment to making ordinary, everyday parts of her life more beautiful, and the styling and threading of such moments together into a story through the recurrence of key signifiers, such as her bicycle and coffee cup.
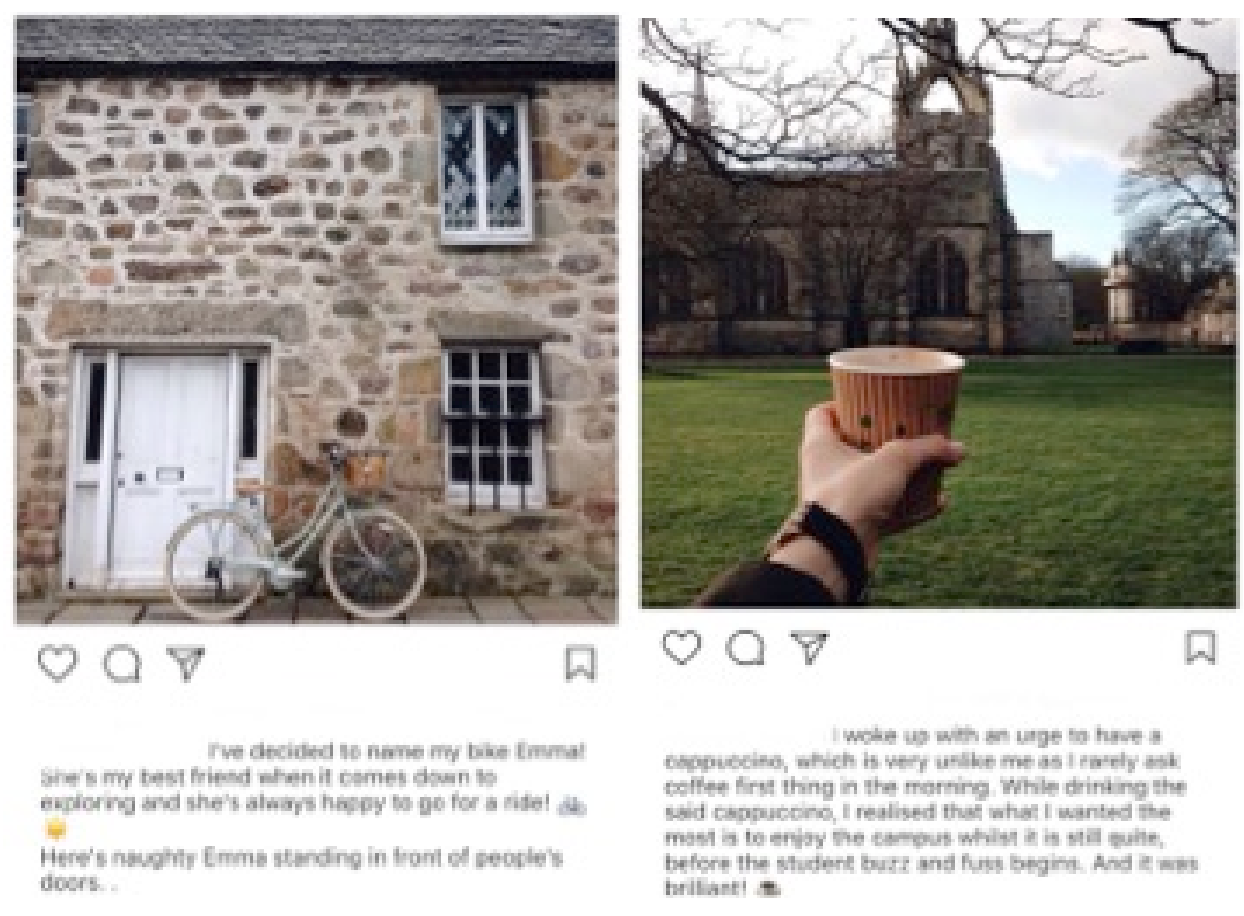

Figure 3: Styling a lifestyle 
When I find a nice place but something is missing, like a cup of coffee or flowers, I always have Emma [bicycle]. So Emma will be there, she will make the picture look prettier and that's it. When they think of me, I want people to think of a girl who has a bike and just goes around Old Aberdeen (Fara, 30)

The use of a coffee cup and bicycle as props (Goffman, 1956) allows Fara to retain a consistent and unique aesthetic on Instagram; enabling these photos of Aberdeen to remain visually recognisable as her own. The fact that her Scottish setting formed a key part of the posts, suggests that Fara was not just styling her own identity on Instagram but also styling and shaping perceptions of Scotland as a place.

Most participants regarded Instagram as a source of enjoyment, something that enriched their lives in some way, where they could record and showcase aspects of their offline lives as well as the evolution of their own personal style (Chittenden, 2010; Palmgren, 2010; Rocamora, 2011; Luvaas, 2013). Some participants spoke of using Instagram as a fashion diary, where they could recollect previous outfits and styles.

\section{Identity evolution on Instagram}

Regardless of their follower numbers or engagement levels, participants dedicated significant effort to constructing and maintaining their online identity. They spent time scrutinising this and often appeared to seek an indefinable perfection. The search for an ideal identity in this way could be seen as an extension of Erikson's (1959) theory, where it is argued that individuals spend their lives seeking to achieve an authentic vision of themselves. This has since been defined by Kinwall (2004: 121) as the pursuit of a "stable" identity or by Kroger (2004: 66) as the "commitment" to a particular identity. These findings support dePerthuis and Findlay's (2019: 234) definition of the "fashionable ideal" on Instagram, which they argue "remains an aspirational, if not mythical, 
figure". However, the participants in this study were not always influenced most strongly by dominant tropes in fashion. Participants in the current research all reflected on the evolution of their online self, where some were still exploring their identity and others felt that they had achieved their ideal identity on Instagram. One way in which participants felt they projected their Scottish style was through making "independent" and more internally motivated fashion choices, which sometimes meant embracing less fashionable styles.

Although participants used Instagram predominantly as an outlet through which they could communicate their own style identity, they also saw it as a place for fashion and lifestyle inspiration; reflecting on their experiences as followers of other influencers and brands. Findlay (2015) observes this relationship in the context of fashion blogs, where bloggers are often inspired by others in the field. Even the most career minded of the current research participants felt that the openness and honesty she shared with her followers played a critical part in her success and spoke of taking time to "engage", i.e. respond to comments/ messages and like/ comment on others' posts. This sense of inspiration was also related to fashion content where, for example, some participants spoke about being inspired by other Scottish influencers to be more daring with their own personal style.

As with fashion blogs as a genre, Instagram was recognised by participants as a place where they could experiment with their style, seek feedback and hopefully gain acceptance from their audience (Turkle, 1995; Vaast, 2007; Whitworth, 2009; Chittenden, 2010; Palmgren, 2010; Rocamora, 2011; Luvaas, 2013). A successful identity on Instagram, or the achievement of an ideal self (Erikson, 1959) appeared to be measured, at least in part, by the acquisition of followers, engagement on posts (likes and comments) and receipt of commercial opportunities from PR agencies and brands. Participants felt their frontstage identity as projected through Instagram was truthful and often relatable, where they presented a realistic version of themselves in line with their offline, backstage self (Goffman, 1956). However, they were conscious of their audience when posting and this consciousness often influenced their online behaviour in 
terms of the styles and experiences they chose to share (Chittenden, 2010; Rocamora, 2011).

Titton (2015: 208) observes the "struggle between consistency and discordance" amongst fashion bloggers who attempt to strike a balance between what is shared (popular culture and style) and what is their own (originality of their own personal style, tastes and opinions) then attempt to form this into a logical narrative. The current research revealed a relationship between the projection of a consistent style aesthetic (construction of an ideal identity by the influencer) and external authenticity (identity as it was perceived by followers); where participants felt that an audience would perceive the portrayal of consistent style on Instagram as more genuine and believable. When discussing their personal style on Instagram, some referred to a signature pose or image composition, which they believed that followers would recognise as inherently belonging to them. These ideas illustrate the applicability of Erikson's (1959) theory as well as Kroger (2004) and Kinwall's (2004) extension of his work.

The participants in this study all used Instagram in a professional manner and regarded this, at least partly, as a career. However, some were more career orientated than others. The portrayal of a consistent and distinctive style identity was particularly important to the most career-minded participant, who had the highest follower numbers at 54k. Jura (25) chose to edit all her images before uploading these to Instagram; moving away completely from the realtime appeal that is usually associated with the platform, where an influencer might shoot, filter and post an image immediately (Song, 2016; MacDowell and de Souza e Silva, 2018). She felt she portrayed a realistic version of her offline style by showing herself in and around her hometown of Glasgow in the clothes she was wearing that day: "just putting on jeans and a t-shirt and a blazer - that literally it is my day. I wear that on a daily basis and I go out and shoot". This is revealing in the context of a fashion influencer's "career", where offline style is often influenced by a need to be photographed in order to fulfil commercial obligations, as well as create exciting content for Instagram. This demonstrates further the tension and mutual dependency of an online and offline identity 
(Turkle, 1995; Chittenden, 2010; Hardey, 2002).

Jura made the conscious decision to withhold more personal, backstage moments from her day-to-day life, preferring to focus her online identity entirely on fashion and thinking of herself in a business-like way (Pedroni, 2017). In her sample posts, Jura presented herself looking away from the camera, in a conscious effort to ensure her identity remained focused on the garments she was wearing. She reflected on her choice of posts saying, "they speak of me so strongly, they just have my style written all over them". Not only was Jura conscious of her personal style in clothes, but also her personal style in posts. She was mindful of which of her posts "do the best" (i.e. receive the most likes and comments) and had tailored her content to suit the tastes of her audience (Chittenden, 2010; Rocamora, 2011). For Jura, it seemed that an ideal identity on Instagram had already been achieved and she was working to maintain this by projecting a consistent style, which she applied to all aspects of her online self, i.e. clothing, setting, photography and pose.

Other participants agreed that consistency and originality were important and, although they felt they had not yet achieved this on Instagram, it was something they strove towards as an ideal. One participant revealed light-heartedly that her images were not carefully curated and beautiful and felt this was probably why she was "not that successful". This illustrates the relationship between achieving an ideal identity on Instagram (Erikson, 1959), constructing and maintaining a consistent style on Instagram (Kinwall, 2004; Kroger, 2004) and perceived success on the platform.

Those participants who were less established in their follower numbers and used Instagram in a less business-like way (Rocamora, 2018), tended to present themselves in a more experimental manner; using the platform as a creative outlet through which they could test new styles in order to find out what their audience enjoyed, as well as what they themselves liked best (Vaast, 2007; Whitworth, 2009; Chittenden, 2010; Palmgren, 2010; Rocamora, 2011; Luvaas, 2013). One participant reflected on the evolutionary aspect of her online identity 
saying, "I feel like I'm still getting there... I'm still finding out what I like and what I don't like, I'm definitely still experimenting". This supports the idea that a key motivation for using Instagram (one that is perhaps still relatively unique to the platform) is that of creativity (Sheldon and Bryant, 2015; Dumas et al, 2017).

The findings of this study support the idea of an online identity lifecycle. Although Erikson (1959) suggests identity achievement might be a never-ending process, where motivations and aspirations will evolve throughout the lifetime of an individual, the behaviour and beliefs of the participants in this study suggests that this might be realised more absolutely on Instagram, where feedback can be gathered and success can be measured. However, in a fashion context (where styles and aesthetics constantly change and evolve), an influencer is likely to have to adapt their personal style if they wish to retain a more commercial level of a success. Once an influencer has achieved their ideal identity, they must then work to retain this level of accomplishment and, presumably, there will be subtle shifts throughout the "lifetime" of the influencer. Indeed these shifts might be conscious or unconscious.

These findings illustrate a spectrum of identity evolution in influencer behaviour on Instagram (Figure 4), ranging from what might be regarded as the more exploratory and natural to the more constructed and stylised. The less careerminded influencers appeared to enjoy content creation more and expressed a freedom, where they felt better able to experiment with their personal style. The more career-minded influencers chose to portray themselves in a more predictable and one-sided manner, enhancing specific aspects frontstage, whilst concealing other elements of their backstage self (Goffman, 1956); these decisions were motivated most strongly by a sense of their audience. 
External influences

Fashion trends

Technological innovations

Audience reception

Commercial opportunities

Seasonality

\section{Internal influences \\ Sense of self \\ Sense of style \\ Sense of place Mood}

Exploratory identity

Fluid and evolving

Ideal identity

Internal authenticity

Fixed and maintained

External authenticity

Figure 4: Spectrum of identity evolution on Instagram

The findings suggest that, once participants feel they have achieved an ideal identity on Instagram (Erikson, 1959), they will begin to stabilise their personal style and portray a less varied and multi-faceted version of themselves (Kinwall, 2004; Kroger, 2004). Two of the more career-minded participants appeared to feel they had reached this stage. This was conveyed through the application of a consistent aesthetic and personal style, where they described their use of consistent settings, poses, props, colours, filters and style choices. Participants appeared to have a heightened awareness of their audience and spoke about using metrics and analytics to measure success. They also appeared more constrained in their use of Instagram and enjoyed using it less than those who were still exploring and experimenting with their online identity.

The complex notion of authenticity is highlighted in the variety of works that underpin this research topic; for example Scottish identity (McCrone et al, 1995), online identity (Turkle, 1995), fashion bloggers (Marwick, 2013; Titton, 2015) and fashion influencers (Marwick, 2015). In all these contexts, it is argued that the definition of authenticity has changed and is increasingly more concerned with projecting a constructed and stylised - perhaps even predictable and exaggerated - representation of what is real. In the context of Scottish identity and heritage, McCrone et al (1995: 20) describe this as the tension between what 
is real and "what is believable". The current research illustrates further the complexity of this concept.

The maintenance of an ideal identity on Instagram (once this has been achieved) appears to rest more on external influences such as audience perception and understanding of the Instagram algorithm, rather than internal influences, which were more manifest in those who were still exploring their identity on Instagram. Therefore, the most career-minded participants were arguably presenting a less open version of their offline self, despite its external appearance of greater authenticity.

\section{Constructing Scottish identity and place online using Instagram}

The participants in this study all revealed themselves as Scottish, Scotland-based or as physically placed within a Scottish city as part of a character-limited biography on Instagram. This could be considered a conscious decision and perhaps an explicit reference to their national identity and place. In an online world, which knows no geographic boundaries and where influencers could choose to remain placeless (Luvaas, 2013), their decision to reveal their national identity and place in this way suggests this is a salient marker of their frontstage self (Goffman, 1956).

Participants all regarded Scottish identity, for the most part, in a highly positive light: they felt this was an attractive feature and something that made them stand out in the increasingly crowded realm of influencers online. They felt that Scottish identity was both a recognisable trait and a point of interest.

Participants understood their audience to be made up partly of Scottish people, who they felt could relate to their identity as a Scottish fashion influencer. They also recognised their non-Scottish followers, who they felt might regard Scottish identity and place as attractive. 
When asked about how they revealed their Scottish identity online, participants drew on personal memories and offline experiences. They remembered positive experiences of being recognised as Scottish outside of Scotland - when travelling, visiting and/ or living in other countries. One reflected on the warm reception she received as a Scottish person during trips abroad and when living and studying abroad on two separate occasions. By labelling themselves as Scottish on Instagram, it appeared that participants hoped to attract positive engagement from people online, mirroring their offline experiences. It did not seem to be participants' intentions to blend into an existing community of Scottish style influencers, so much as to expand their own appeal beyond this, utilising what they saw as the positive reception of Scottishness. Instagram might therefore be regarded as another destination outside of Scotland, where an influencer can use their national identity and physical setting to stand out.

Scottish identity was more salient to some participants who were found to be revealing this more consciously than others. Iona (23) spoke of styling herself with her Scottish identity in mind, where both her Scottish and her Instagram identity influenced her hair colour respectively. She recognised red hair as a stereotype of Scottish people and felt that the unnatural brightness of her own hair and vibrant fashion choices made her stand out on Instagram (Figure 5). This was probably the only example where a participant reflected on "looking Scottish" in this way. Most participants referred to Scottish stereotypes such as ginger hair, pale skin and tartan with amusement but did not feel they were reflective of contemporary Scottish identity and style; or indeed that these characteristics were exclusive to Scotland. 


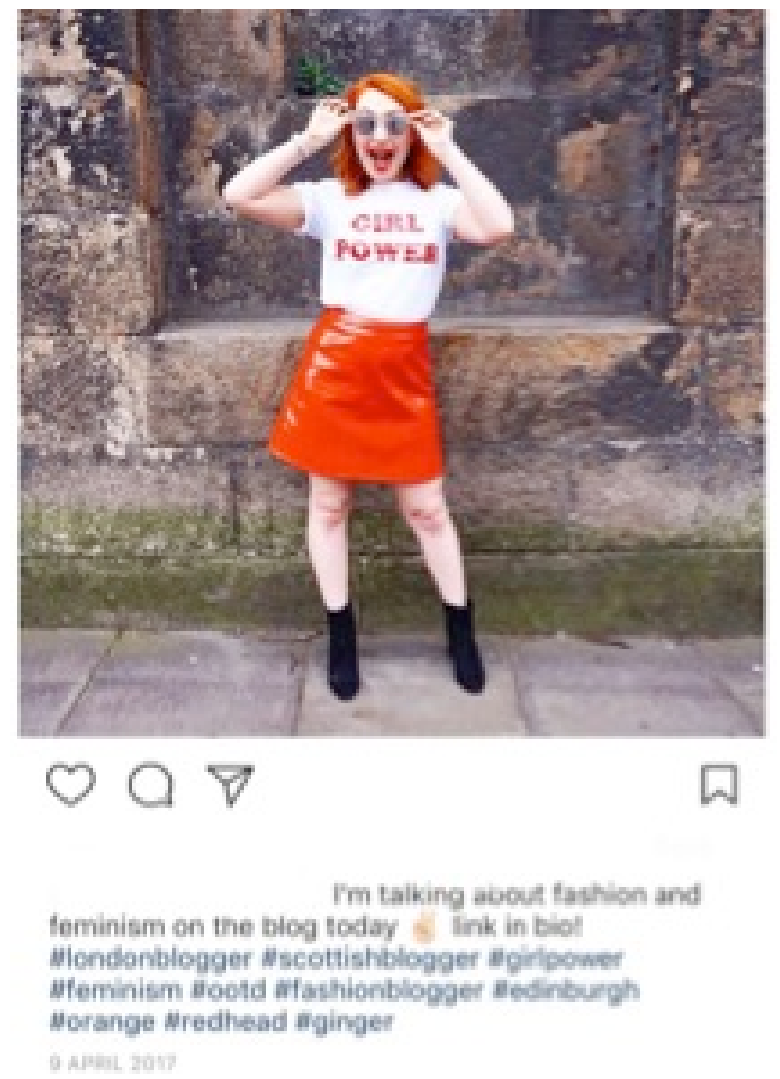

Figure 5: Scottish style

The participants in this study were concerned with portraying what they termed a "relatable" identity to their followers. Cara (21) felt that this made Scottish bloggers different to their London counterparts:

I'm just kicking about Glasgow, sharing the food I want to eat... I'm not... for example the London scene - where it's all super glossy and fancy restaurants and the amazing outfit shots in front of the big white houses... It's just a lot more me instead of like a magazine-style glossyeditorial kind of thing.

This assumption appeared to be based almost entirely on Cara's idea of herself as a "Scottish blogger", where her sense of being relatable seemed to stem from a sense of national identity and place. There was a consensus amongst all participants that Scotland was a small nation but one that had resonance amongst a global audience; they felt this made Scotland relevant and that this in turn made them appear more down-to-earth and relatable to their followers. In 
comparison, the identity of a "London blogger" was seen by participants as more aspirational and less applicable. Note, however, Cara's tendency to share the food she wants to eat and not necessarily always the food she is eating.

Participants used hashtags and small, familiar phrases like "wee" and "bonny" in order to appear relatable within the Scottish style community. However, they also believed that using hashtags like \#ScottishBlogger, \#EdinburghBlogger and \#ScotStreetStyle would attract commercial opportunities from brands that might hope to reach a Scottish audience. All were able to give examples of opportunities they had received because of their Scottish associations on Instagram. Although the use of hashtags might be considered conscious and explicit, participants were found to use these in a banal manner, where they were often applied to all posts regardless of the content (Billig, 1995).

Participants favoured outdoor photography and were found to construct an image of Scotland in their use of place and setting (Figure 6). They all lived in cities but chose to adopt unique backdrops for style posts, mostly in the form of natural settings or those that connote a sense of history or heritage. Through their depiction of cobbled streets in Edinburgh, heritage attractions in Aberdeenshire and the uninterrupted Scottish landscape, Scottish fashion influencers are redefining the traditional street-style aesthetic (Rocamora and O’Neill, 2008). However, they are arguably also further embedding Scottish heritage iconography of the nation as a stark and peopleless place (McCrone et $a l, 1995)$. Sometimes participants were conscious in their use of these backdrops, setting out and planning posts, and at other times this was more impulsive, where the discovery of an interesting setting would inspire them to post. 


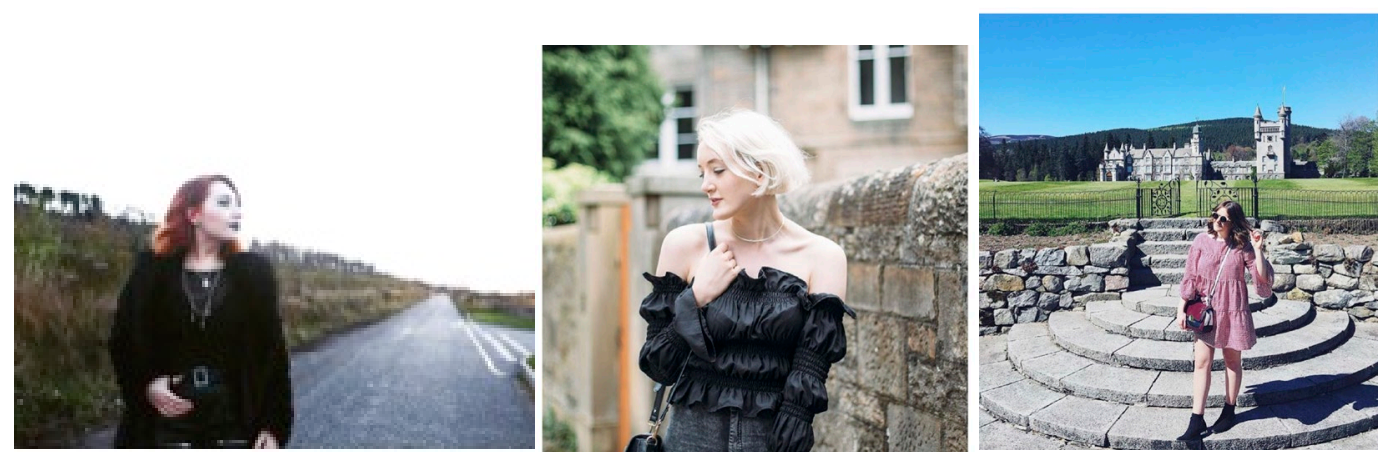

Figure 6: Scottish street style

These findings illustrate some of the ways in which an influencer's personal style as it appears online might be influenced by a sense of national identity and place.

\section{Conclusions and implications for future research}

This study builds on existing theories of self presentation and identity through an exploration of fashion influencers who position themselves as Scottish on Instagram. Participants were not found to be constructing an Instagram identity (frontstage) that was vastly different from their offline identity (backstage) (Goffman, 1956) but they generally chose to curate a preferred rather than an everyday representation of their style. At times, participants' offline activities and fashions were actually influenced by a desire to share these with their followers on Instagram. This supports other studies of fashion blogging and influence that report similar findings amongst research subjects and participants.

This research sought to further understand the influencer phenomenon by focusing on a specific national context and platform, where the influencer community in Scotland is relatively small, consisting mostly of nano and micro influencers. The issue of authenticity was complex and a spectrum of identity evolution on Instagram is observed and reflected on. Participants were found to seek an ideal identity on Instagram and this was projected through their fashion and lifestyle content (Erikson, 1959). All were conscious of their audience and sought to manage their appearance (Goffman, 1956). The most career minded of 
the participants seemed to have discovered their ideal identity on Instagram and used this to carve out a niche on the medium; however, given how conscious they were of their audience, this might suggest a more superficial level of identity achievement (Erikson, 1959).

These findings illustrate the use of national or local identity and place on Instagram as an asset, something that might become even more significant as the infosphere continues to grow and evolve and where influencers will undoubtedly seek new ways to stand out and be unique. Scotland is distinctive in terms of its fashion iconography, which is rooted in its textiles industry, but lacks a fashion media landscape. Therefore fashion influencers who position themselves outwardly as Scottish might be seen as particularly significant in shaping contemporary ideas of the nation.

In terms of national identity and place, these Scottish fashion influencers were found to convey this explicitly as a characteristic in their biography and through the use of hashtags and small familiar phrases. Only one participant styled her appearance consciously with her Scottish identity in mind but others were found to convey this in more subtle ways: through their preference for outdoor imagery participants were not only styling themselves but also styling perceptions of Scotland. For the participants in this study, Scottish identity was seen as an asset and something that was authentic and true. However, some of the ways in which they imagined and conveyed this online further connote a romantic and heritage-driven Scottish myth, which is regarded today as stylised and, perhaps therefore, inauthentic (McCrone et al, 1995).

This research contributes to the growing body of work in fashion studies and particularly fashion blogging and influence. The study comprised a small sample of all female influencers, who were not a diverse group in terms of age, socioeconomic status and education. This could be considered reflective of the Scottish style community on Instagram at the present time but future work might explore Scottish identity from the perspective of male influencers or 
minority communities in order to gain insights into their online behaviours and experiences as well as their unique insights into contemporary Scottish style.

The findings presented in this article are situated from the perspective of the participant influencers themselves and the researcher's interpretation of their experiences and output; both possess a degree of insider knowledge and understanding of the phenomenon. This analysis does not take into account the polysemous nature of imagery and so future work might seek to understand followers' perceptions of influencer identities and content, for example in order to further understand the concept of authenticity.

This work is exploratory and further work is invited to build on these findings by investigating the portrayal of national identity by fashion influencers in other geographic contexts.

\section{References}

Abidin C (2016) Visibility labour: engaging with influencers' fashion brands and \#00TD advertorial campaigns on Instagram. Media International Australia 161(1): 86-100.

Allen C (2009) Style surfing: changing parameters of fashion communication where have they gone? In: $1^{\text {st }}$ Global conference: Fashion exploring critical issues. 25-27th September 2009. Mansfield College: Oxford.

Au-Yong-Oliveira M, Cardoso AS and Gonçalves M et al (2019) Strain effect: a case study about the power of nano-influencers. In 2019 14th Iberian Conference on Information Systems and Technologies (CISTI), pp 1-5. IEEE.

Barthes R (1957) Image/ music/text. Paris: Editions du Seuil.

Billig M (1995) Banal nationalism. London: Sage Publications Ltd.

Blalock M (2016) 7 secrets to becoming a successful fashion blogger. Who What Wear. Available at: http://www.whowhatwear.co.uk/how-to-become-ablogger/ (accessed 14 February 2017).

Bobb B (2018) Why you should let these 10 Instagram accounts feed your fashion creativity. Vogue. Available at: 
https://www.vogue.com/article/global-100-fashion-Instagram-

inspiration (accessed 29 May 2018).

Bourdieu P (1986) The forms of capital. In Richardson JE (ed) Handbook of theory of research for the sociology of education. Westport, CT: Greenwood Press.

Bullingham L and Vasconcelos AC (2013) The presentation of self in the online world: Goffman and the study of online identities. Journal of Information Science 39(1): 101-112.

Butler J (1988) Performative acts and gender constitution: an essay in phenomenology and feminist theory. Theatre Journal 40(4): 519-531.

Casaló LV (2018) Influencers on Instagram: antecedents and consequences of opinion leadership. Journal of Business Research. In press.

Chittenden T (2010) Digital dressing up: modelling female teen identity in the discursive spaces of the fashion blogosphere. Journal of Youth Studies 13(4): 505-520.

Craik J (2002) Book review: out of line: Australian women and style by Margaret Maynard (UNSW Press, 2001). Fashion Theory: the Journal of Dress, Body and Culture 6(4): 457-62.

Craik J (2009) Is Australian fashion and dress distinctively Australian? Fashion Theory: the Journal of Dress, Body and Culture 13(4): 409-422.

Crane TC, Hamilton JA and Wilson LE (2004) Scottish dress, ethnicity and selfidentity. Journal of Fashion Marketing and Management 8(1): 66-83.

de Perthuis, K. and Findlay R (2019) How fashion travels: the fashionable ideal in the age of Instagram. Fashion Theory: the Journal of Dress, Body and Culture. 23(2): 219-242.

Duffy BE and Hund E (2015) Having it all on social media: entrepreneurial femininity and self-branding among fashion bloggers. Social Media and Society. 11.

Dumas TM Maxwell-Smith M Davis JP et al (2017) Lying or longing for likes? Narcissism, peer belonging, loneliness and normative versus deceptive like-seeking on Instagram in emerging adulthood. Computers in Human Behaviour 71: 1-10.

Erikson E (1959) Identity and the lifecycle. New York: Norton \& Company Inc. 
Findlay R (2015) The short, passionate, and close-knit history of personal style blogs. Fashion Theory: the Journal of Dress, Body and Culture 19(2): 157178.

Goffman E (1956) The presentation of self in everyday life. London: Penguin Books.

Goodrum AL (2009) True Brits? Authoring national identity in Anglo-Japanese fashion exports. Fashion Theory: the Journal of Dress, Body and Culture 13(4): 461-479.

Hänninen R (2015) Is this an advertisement or a personal account?

Commercialisation of lifestyle blogs in Finland. Social Networks, Communication and the Internet. 42: 54-69.

Hardey M (2002) Life beyond the screen: embodiment and identity through the Internet. The Sociological Review 50(4): 570-585.

Harju AA and Huovinen A (2015) Fashionably voluptuous: normative femininity and resistant performative tactics in fashion blogs. Journal of Marketing Management 31: 1602-1625.

Hogan B (2010) The presentation of the self in the age of social media: distinguishing performances and exhibitions online. Bulletin of Science, Technology and Society. 30(6): 377-386.

Hoover K (2004) The future of identity: centennial reflections on the legacy of Erik Erikson. Oxford: Lexington Books.

Johnson M (2019) Nano influencers: the next big thing. Power Digital Marketing. Available at: https://powerdigitalmarketing.com/blog/nano-influencersthe-next-big-thing/ (accessed 18 March 20190.

Kiely R Bechhofer F Stewart R et al (2001) The markers and rules of Scottish national identity. The Sociological Review 49(1): 33-55.

Kinwall C (2004) Globalisation, identity, and the search for chosen traumas. In Hoover K (ed) The future of identity: centennial reflections on the legacy of Erik Erikson. Oxford: Lexington Books, pp.111-136.

Klein A (2014) Is Instagram killing personal style blogs? Fashionista. Available at: http://fashionista.com/2014/06/will-instagram-kill-fashion-blogs. (accessed 5 March 2017). 
Kroger J (2004) Identity in formation. In Hoover K (ed) The future of identity: centennial reflections on the legacy of Erik Erikson. Oxford: Lexington Books, pp.61-76.

Larkin M and Thompson A (2012) Interpretative phenomenological analysis. In Thompson A and Harper D Qualitative research methods in mental health and psychotherapy: a guide for students and practitioners, pp. 99-116. Oxford: John Wiley \& Sons.

Liu R. and Suh A (2017) Self-Branding on Social Media: An Analysis of Style Bloggers on Instagram. Procedia Computer Science 124:12-20.

Lövheim M (2013) Negotiating emphatic communication: Swedish female topbloggers and their readers. Feminist Media Studies. 13(4): 613-628.

Luvaas B (2013) Indonesian fashion blogs: on the promotional subject of personal style. Fashion Theory: the Journal of Dress, Body and Culture 17(1): 55-76.

McCrone D Morris A and Kiely R (1995) Scotland the brand. Edinburgh: Edinburgh University Press.

McCrone D (2017) The new sociology of Scotland. London: SAGE Publications Ltd. McQuarrie EF, Miller J and Phillips BJ (2013) The megaphone effect: taste and audience in fashion blogging. Journal of Consumer Research 40(1): 136158.

MacDowell JL and de Souza e Silva P (2018) “I'd Double Tap That!!”: street art, graffiti, and Instagram research. Media, Culture and Society 40(1): 3-22.

Maghfiroh L and Hapsari NF (2015) A celebrification of celebgram on Instagram: a case study of @Shireeenz. Allusion 4(1): 57-62.

Marcella-Hood M (2019) Exploring contemporary illustrations of Scottish identity through a study of Scottish fashion influencers on Instagram. Scottish Affairs 28(4): 367-394.

Marwick AE (2013) 'They're really profound women, they're entrepreneurs': conceptions of authenticity in fashion blogging. In 7th international AIII conference on weblogs and social media (ICWSM), July (8).

Marwick AE (2015) Instafame: luxury selfies and the attention economy. Public Culture 27(1): 137-160. 
Moloney A (2017) How to make money on Instagram. Metro. Available at: https://metro.co.uk/2017/11/09/how-to-make-money-on-instagram7064647/ (accessed 22 January 2018).

Mora E and Rocamora A (2015) Letter from the editors: analysing fashion blogs: further avenues for research. Fashion Theory: the Journal of Dress, Body and Culture 19(2): 149-156.

National Records of Scotland (2019) Scotland's population at record high, but population growth has slowed. Available at:

www.nrsscotland.gov.uk/news/2019/scotlands-population-at-recordhigh-but-population-growth-has-slowed (accessed 10 July 2019).

O’Brien D (2016) How influential is Instagram on the fashion industry? Social Media Today. Available at: http://www.socialmediatoday.com/socialnetworks/how-influential-Instagram-fashion-industry-infographic (accessed 12 March 2017).

Palmgren AC (2010) Posing my identity: today's outfit in Swedish blogs. Observatorio 4(2): 19-34.

Panofsky E (1955) Meaning in visual arts. New York: Doubleday Anchor Books.

Pedroni M (2015) Stumbling on the heels of my fashion blog: career forms of capital and strategies in the (sub)field of fashion blogging. Fashion Theory: the Journal of Dress, Body and Culture 19(2): 179-200.

Pedroni M, Sádaba T and SanMiguel P (2017) Is the golden era of fashion bloggers over? In: Mora E and Pedroni M (eds) Fashion tales: feeding the imaginary. Bern: Peter Lang.

Penchansky R Mason N and Yambao BG (2018) The evolution of the influencer economy. Business of Fashion. Available at: https://www.businessoffashion.com/articles/sponsored-feature/theevolution-of-the-influencer-economy (accessed 11 February 2019).

Pham MT (2011) Blog Ambition: Fashion, Feelings, and the Political Economy:sêpiof the Digital Raced Body. Camera Obscura 76(26): 1-37.

Riegels Melchior M (2010) Doing Danish fashion: on national identity and design practices in a small Danish fashion company. Fashion Practice 2(1): 13-40. 
Rocamora A and O'Neill A (2008) Fashioning the street: images of the street in the fashion media. In Shinkle E (ed) Fashion as photograph. London: I.B. Taurus \& Co., pp.185-199.

Rocamora A (2009) Fashioning the city: Paris, fashion and the media. London: I. B. Tauris \& Co.

Rocamora A (2011) Personal fashion blogs: screens and mirrors in digital selfportraits. Fashion Theory: the Journal of Dress, Body and Culture 15(4): 407-424.

Rocamora A (2018) The labour of fashion blogging. In: Armstrong L and McDowell F (eds) Identity and representation at work in the creative industries. London: Bloomsbury.

Scheff TJ (2006) Goffman unbound! A new paradigm for social science. Oxon: Routledge.

Schwartz R and Halegoua GR (2015) The spatial self: location-based identity performance on social media. New Media and Society 17(10): 1643-1660.

Serge Reinach S (2015) National identities and international recognition. Fashion Theory: the Journal of Dress, Body and Culture 15(2): 267-272.

Sheldon P and Bryant K (2015) Instagram: Motives for its use and relationship to narcissism and contextual age. Computers in Human Behaviour 58: 89-97.

Skov L (2010) Dreams of small nations in a polycentric fashion world. Fashion Theory: the Journal of Dress, Body and Culture 15(2): 137-156.

Smith JA (2004) Reflecting on the development of interpretative phenomenological analysis and its contribution to qualitative research in psychology. Qualitative Research in Psychology 1(1): 39-54.

Song A (2016) Capture your style. Abrams: New York.

Summers JO (1970) The identity of women's clothing fashion opinion leaders. Journal of Marketing Research 7(2): 178-185.

Titton M (2015) Fashionable personae: self-identity and enactments of fashion narratives in fashion blogs. Fashion Theory: the Journal of Dress, Body and Culture 19(2): 201-220.

Tomiuc A and Stan $O$ (2015) The fashion blogosphere in Romania: fashionscape and fashion bloggers. Postmodern Openings 6(1): 161-174.

Turkle S (1997) Life on the screen: identity in the age of the Internet. New York: 
Touchstone.

Vaast E (2007) Playing with masks: Fragmentation and continuity in the presentation of self in an occupational online forum. Information Technology and People 20: 334-351.

Van House NA (2009) Collocated photo sharing, story-telling and the performance of self. International Journal of Human-Computer Studies 67: 1073-1086.

Whitworth A (2009) Information obesity. Oxford: Chandos.

Young C and Martin A (2017) Tartan and tweed. London: Frances Lincoln Limited.

Zhao S (2006) Cyber-gathering places and online-embedded relationships. In: Paper presented at the annual meetings of the Eastern Sociological Society in Boston. 